\title{
In vitro repellency evaluation of selected botanical extracts against cigarette beetle, Lasioderma serricorne
}

Waseem Kamal ${ }^{1}$, Sajjad Ahmad ${ }^{2}$, Muhammad Saeed ${ }^{3}$, Abdur Rehman², Hayat Zada ${ }^{1}$, Abdul Latif ${ }^{2}$, Taimur Khan ${ }^{2}$ and Sami Ullah ${ }^{2}$

1. Department of Agriculture Extension KP-Pakistan

2. Department of Entomology, Faculty of Crop Protection Sciences, The University of Agriculture Peshawar-

Pakistan

3. Department of Agriculture Sciences, The University of Haripur KP-Pakistan

*Corresponding author's email: rehmanento@gmail.com

Citation

Waseem Kamal, Sajjad Ahmad, Muhammad Saeed, Abdur Rehman, Hayat Zada, Abdul Latif, Taimur Khan and Sami Ullah. In vitro repellency evaluation of selected botanical extracts against cigarette beetle, Lasioderma serricorne. Pure and Applied Biology. Vol. 8, Issue 1, pp208-214. http://dx.doi.org/10.19045/bspab.2018.700178

\begin{tabular}{llll}
\hline \hline Received: 05/04/2018 & Revised: 24/10/2018 & Accepted: 25/10/2018 & Online First: 02/11/2018 \\
\hline
\end{tabular}

\section{Abstract}

To investigate the percent repellent outcomes of the chosen botanical extracts against adults cigarette beetle (Lasioderma serricorne Anobiidae: Coleoptera) an experiment was carried out at the Entomology Section, Department of Agricultural Sciences, University of Haripur, in 2015. Two native botanical extractions obtained from Mentha longifolia (Mint) Lamiaceae and Momordica charantia (Bitter Gourd) Cucurbitaceae were tested for finding the repellent outcomes against Lasioderma serricorne while exposing them for ten days. The concentrations of botanical materials were 25, 50 and $75 \%$. Each treatment was replicated three times with completely randomized design (CRD). Outcomes confirmed that highest repellency was observed at tenth day of exposure by $M$. longifolia i.e. $86.667 \%$ at $75 \%$ concentration versus $L$. serricorne, followed by $M$. charantia at the same dose $(75 \%)$ where the percent repellency was 76.67 . The experiment further confirmed that as the exposure time and the concentrations increased the percent repellent outcomes of the L. serricorne also increased.

Keywords: Concentration; Lasioderma serricorne; Plant extracts; Repellency; Time exposure

\section{Introduction}

Tobacco is mainly cultivated in Khyber Pakhtunkhwa (KP) Pakistan. The main growing areas include viz., Buner, Charsadda, Swabi, Swat, Mardan and Manshera. Nicotiana tabacum $\mathrm{L}$ and $N$. rustica $\mathrm{L}$ are the main species which are cultivated in these areas [1]. At national level it attributes Rs. 34 billion to GDP along foreign earning of Rs. 587 million by the cigarette manufactures. It generates six times more excise duty than cotton yarn [2]. Globally, stored product pests cause significant losses to storage commodities. In Pakistan, these losses are varied from 10 to $25 \%[3,4]$. The cigarette beetle, Lasioderma serricorne is a serious pest of stored products and causes considerable losses and has been regularly reported in most of the tropical and sub-tropical regions while feeding on all types of tobaccos like flue cured, rustica, burley and oriental tobaccos [5]. Similarly, 
the preferred way of controlling L. serricorne is by using insecticides. Pyrethroids are used for crawling and flying populations while Aluminum phosphide is used against all stages in the form of fumigants. But the research showed that consistent uses of synthetic insecticides are causing negative effects on the environment and also on nontargeted organisms. Similarly, insecticides create problems of resistance in the target pests. [6]. So it is necessary to find safe crop protecting agents for their control [7, 8]. Some plant extracts have been reported with numerous negative effects on insects $[7,9$, 10]. Botanical extracts are highly selective, simple to decompose, offer no residual effects, and trigger no contamination or risks to man and environment $[11,12]$. In previous studies, the bioactivities of a large number of botanical oils have been also assessed verses number of insects found in stores [13, 14]. Based on the significance of plant extracts nature, this research was conducted to check the efficacy of various plant materials viz., Momordica charantia and Mentha longifolia against $L$. serricorne adults to investigate the percent repellent effects of chosen botanical extracts against $L$. serricorne adults in laboratory settings and to find out the effects of different concentrations of the chosen botanical extracts at different times of exposure.

\section{Materials and methods}

The experiment was carried out at the Department of Agricultural Sciences Entomology section, University of Haripur during 2015 to investigate the percent repellent outcomes of the chosen botanical extracts versus adult Lasioderma serricorne.

\section{Test materials}

Botanical materials utilized in the experiment were Mentha longifolia (T1) and Momordica charantia (T2). The above botanical materials were purchased from local market in District Haripur and then rinsed followed by drying at controlled temperature and relative humidity i.e., $27 \pm 2^{\circ} \mathrm{C} \& 75 \pm 5 \%$. Plant materials were extracted via the acetone solvent for extraction (100g of each sample in $75 \mathrm{ml}$ of ethyl alcohol). The extracts were properly dried and stored in sealed glass vials in refrigerator. These botanical extracts then assessed for their repellency versus the adults of $L$. serricorne to determine the effective plant extract, percent concentration and exposure period.

\section{Rearing and maintenance of insects culture}

The checked insects were taken from laboratory cultures kept in incubators at $30 \pm 2$ ${ }^{\circ} \mathrm{C} \& 73 \pm 5 \%$ relative humidity $(\mathrm{RH})$. Wheat flour with Baker's yeasts $(20: 2 \mathrm{w} / \mathrm{w})$ was the food source for insects at 12- $12.5 \%$ humidity. Collection of eggs was done by keeping the adults on filter papers for 45 hours. When eggs were hatched, then the larvae were shifted to other cages for maturity. Seven days older beetles were taken in petri dishes (10 adults per petri dish) and the botanical extracts were applied on them for finding their repellency. Poly tetrafluoreo ethylene (Fluoen) coating was done to avoid escaping of insects from the petri dishes.

\section{Repellency}

From the stock solution, various concentrations $(25,50 \& 75 \%)$ of each plant extract were prepared by using acetone as a diluting solvent. The concentrations of test materials were obtained by taking 25,50 and $75 \mathrm{ml}$ of each extract in $100 \mathrm{ml}$ of acetone to make 100 percent solution. The test solution was applied to each half of a filter paper disk. The control half was treated with acetone only. Filter papers were allowed to dry in open air for 10 minutes to evaporate the acetone. The diluted concentrations were used for subsequent experiments. Thirty mature beetles (seven days older) were released at the center of petri dish. In order to avoid the death of insects due to unavailability of food, a small quantity of diet 
was kept at the either side of the petri dishes. Percentage repellency was determined by calculating the numbers of adults in treated $\&$ untreated areas repeatedly over the period of ten days. Each treatment was replicated thrice. Percentage repellency (PR) values were found out via the approach showed by [15].

$\mathrm{PR}(\%)=\left[\left(\mathrm{N}^{*}{ }_{\mathrm{C}}-\mathrm{N}^{*}{ }_{\mathrm{t}}\right) /\left(\mathrm{N}^{*} \mathrm{C}+\mathrm{N}^{*} \mathrm{t}\right)\right] \times 100$

So as $\mathrm{N}^{*} \mathrm{c}$ shows number of beetles at untreated area and $\mathrm{N}^{*} \mathrm{~T}$ shows beetles numbers at treated area.

\section{Data analyses}

The experiment was laid out in completely randomized design (CR, design) with four replications. Collected data were statistically analyzed using computer statistix (B) 8.1 software. The least significant difference (LSD) at 5\% level of significance was exploited to compare the treatments means [16].

\section{Results and discussion}

\section{Percent repellency at $\mathbf{1}^{\text {st }}$ day of exposure}

Lasioderma serricorne was exposed to botanical extracts viz. Mentha longifolia and Momordica charantia to the concentrations of $25 \%, 50 \%$ and $75 \%$ and $0 \%$ (control) so to find out their repellent outcomes. Amongst the tested botanical extracts $M$. longifolia showed repellent results of $26.67 \%$ at the concentration of $25 \%$ (Table 1) after 24 hours (1day) while M. charantia showed 20\% (Table 2) repellent results. The percent repellent results observed on $50 \%$ concentration were 33.33 by $M$. longifolia and 30 by $M$. charantia as shown in (Table 1 \& 2). At $75 \%$ concentration $M$. longifolia proved repellency of $56.67 \%$ which was similar with the findings of [17] who found that $M$. longifolia is most effective versus pests in stores at $75 \%$ concentration while $M$. charantia gave $46.67 \%$ repellent values respectively. The data further indicates that at control (0\%) no repellency had been observed.

\section{Percent repellency at $2^{\text {nd }}$ day of exposure}

At the second day of exposure $M$. longifolia triggered percent repellent value of $30 \%$ at $25 \%$ concentration while $M$. charantia showed repellent value of $23 \%$ at the same concentration. At $50 \%$ concentration $M$. longifolia caused repellency of $36.67 \%$ and M. Charantia caused $33.33 \%$. At the concentration of $75 \%$ repellency of $60 \%$ had been provided by $M$. longifolia while $M$. charantia showed $50 \%$ as shown in (Table 1 $\&$ 2) respectively. Our results are in accordance with the findings of [18] and who confirmed that $M$. longifolia has significant ability to repel $L$. serricorne and $S$. oryzae in minimum intensity.

Percent repellency at $3^{\text {rd }}$ day of exposure At the third day of exposure $M$. longifolia showed repellent value of $33.33 \%$ at $25 \%$ concentration while $M$. charantia caused repellency of $26.67 \%$ at the same concentration. At $50 \%$ concentration $M$. longifolia caused repellency of $40 \%$ and $M$. charantia caused $36.667 \%$ as shown in (Table $1 \& 2$ ) and these values are supported by [19]. At the concentration of $75 \%$ repellency of $63.33 \%$ was provided by $M$. longifolia and $M$. Charantia showed $53.33 \%$, respectively. At control (0\%) no repellent outcomes were observed.

Percent repellency at $4^{\text {th }}$ day of exposure

The percent repellency results of the tested botanical extracts versus $L$. serricorne over exposure period of ninety-six hours (4 days) showed that $M$. longifolia caused maximum repellency of $36.67 \%$ at $25 \%$ concentration followed by $M$. charantia which caused $30 \%$ repellency (Table $1 \& 2$ ) respectively and these results are matched with the results of [18] who found $M$. longifolia is effective in low concentration against pest in stores. At $50 \%$ concentration $M$. longifolia caused repellency of $43.33 \%$ while $M$. charantia caused $40.00 \%$ correspondingly. Likewise, at the concentration of $75 \%$ repellency of $66.67 \%$ provided by $M$. longifolia while $M$. 
charantia caused $56.67 \%$ repellency. At control $(0 \%)$ no repellent outcomes were observed.

\section{Percent repellency at $5^{\text {th }}$ day of exposure}

Percent repellent outcomes of the tested botanical extracts against $L$. serricorne over exposure period of one hundred-twenty hours (5 days) showed that at control $(0 \%)$ no repellent outcomes were observed. Maximum repellent values of $40 \%$ at $25 \%$ concentration was observed by $M$. longifolia while $M$. charantia gave the repellent values of $33.33 \%$ respectively. By applying 50\% concentration $M$. longifolia caused repellency of $46.67 \%$ and $M$. charantia showed repellent values of $43.33 \%$ as shown in (Table $1 \& 2$ ) At the concentration of $75 \%$ repellency of $70 \%$ proved by $M$. longifolia while $M$. charantia gave $60 \%$ repellency. These results are in close accordance with the results of [20] who found the above botanical extracts effective versus pests in stores in the tested concentrations.

\section{Percent repellency at $6^{\text {th }}$ day of exposure}

Percent repellent results of plant extracts versus $L$. serricorne at the exposure period of one hundred forty-four hours (6 days) indicates that at control $(0 \%)$ no repellency had been observed. M. longifolia gave the outmost repellent values of $43.33 \%$ at $25 \%$ concentration while $M$. charantia gave repellent values of $36.67 \%$ (Table $1 \& 2$ ). These results are supported by the findings of [21] who reported that $M$. longifolia showed repellency against stored pests in low concentration compared to other tested botanical extracts. Applying concentration of $50 \%$ M. longifolia caused repellency of $50 \%$ as compared with $M$. charantia whose repellent values was $46.67 \%$. At the concentration of $75 \%$ repellency of $73.33 \%$ provided by $M$. longifolia while $M$. Charantia showed $63.33 \%$ repellency. Our results are comparable with the findings of [22] who found $M$. longifolia as a strong agent of repellency versus store product pests at the same concentration $(75 \%)$.

Percent repellency at $7^{\text {th }}$ day of exposure

Percent repellency of plant extracts versus $L$. serricorne at the exposure period of one hundred sixty-eight hours (7 days) showed that $M$. longifolia triggered repellent value of $46.67 \%$ at $25 \%$ concentration while $M$. charantia showed repellent values of $40 \%$. At $50 \%$ concentration $M$. longifolia caused repellency of $53.33 \%$ and $M$. charantia caused $50 \%$ as provided in (Table $1 \& 2$ ) correspondingly and these findings are accordance with the results of [23] who reported $M$. longifolia a best botanical extract which repel insects in stores at medium concentration $(50 \%)$. At the concentration of $75 \%$ repellency of $76.67 \%$ has been showed by $M$. longifolia while $M$. charantia showed $70 \%$ of the repellent values. At control $(0 \%)$ no repellent outcomes were observed.

Percent repellency at $8^{\text {th }}$ day of exposure

Percent repellent outcomes of the tested botanical extracts against $L$. serricorne over for the exposed period of one hundred ninetytwo hours (8 days) applied at the concentration of $25 \%, 50 \%$ and $75 \%$. M. longifolia gave high repellent values of $50 \%$ at $25 \%$ concentration followed by $M$. charantia with the repellent values of $43.33 \%$ correspondingly. Applying concentration of $50 \% M$. longifolia caused maximum repellency of $56.67 \%$ as compared with $M$. charantia where the repellent value was $53.33 \%$ respectively. At the $75 \%$ concentration repellency of $80 \%$ was observed by $M$. longifolia while $M$. charantia caused $70 \%$ repellency as shown in (Table 1,2) and these results are accordance with the findings of [18] who observed that $M$. charantiea provided repellent outcomes of more than $60 \%$. At control $(0 \%)$ no repellency was observed.

Percent repellency at $9^{\text {th }}$ day of exposure Percent repellent effects of the tested plant extracts on L. serricorne after exposure 
period of two hundred sixteen hours ( 9 days) showed that at control $(0 \%)$ no repellent outcomes were observed. $M$. longifolia caused repellent value of $53.33 \%$ at $25 \%$ concentration followed by $M$. charantia which caused repellency of $46 \%$. At $50 \%$ concentration $M$. longifolia showed repellency of $60 \%$ while $M$. Charantia caused 56.67\% repellency. When the concentration was applied @ 75\%, repellency of $M$. longifolia was $83.33 \%$ whilst M. charantia showed $73.33 \%$ repellency (Table $1 \& 2$ ). These results are in accordance with the outcomes of [10] they find out high repellency of $M$. longifolia versus insects in stores.

Percent repellency at $\mathbf{1 0}^{\text {th }}$ day of exposure Percent repellent outcomes of the tested botanical extracts against $L$. serricorne for exposure period of two hundred forty hours (10 days) showed that at control (0\%) no repellency had been observed. $M$. longifolia gave repellent value of $56.67 \%$ at $25 \%$ concentration while $M$. charantia caused $50 \%$ repellency. At 50\% concentration $M$. longifolia showed repellency of $63.33 \%$ while by $M$. charantia caused $60 \%$ repellency. At the concentration of $75 \%$ repellency of $86.67 \%$ was provided by $M$. longifolia and $M$. charantia caused $76.67 \%$ repellency (Table $1 \& 2$ ) and these results strongly matched with the results [18] they declared that $M$. longifolia has the significant ability to repel $L$. serricorne and $S$. oryzae at low concentration. Likewise, $M$. charantia proved to be high efficient botanical extract versus $L$. serricorne after $M$. longifolia.

Table 1. Percent repellency of Mentha longifolia over exposure time of ten days

\begin{tabular}{|c|c|c|c|c|c|c|c|c|c|c|}
\hline \multirow{2}{*}{$\begin{array}{l}\text { Concentr } \\
\text { ation }(\%)\end{array}$} & \multicolumn{10}{|c|}{ Percent repellency of Mentha longifolia over exposure time of ten days } \\
\hline & $\mathbf{1}^{\text {stday }}$ & $2^{\text {nd day }}$ & $3^{\text {rd day }}$ & $4^{\text {th day }}$ & $5^{\text {th day }}$ & $6^{\text {th day }}$ & $7^{\text {thday }}$ & $\mathbf{8}^{\text {thday }}$ & $9^{\text {thday }}$ & 10 $^{\text {thday }}$ \\
\hline $0 \%$ & $0.00 \mathrm{k}$ & 0.00 & $0.00 \mathrm{i}$ & $0.00 \mathrm{k}$ & $0.00 \mathrm{k}$ & $0.00 \mathrm{k}$ & $0.00 \mathrm{j}$ & $0.00 \mathrm{j}$ & $0.00 \mathrm{i}$ & $0.00 \mathrm{k}$ \\
\hline $25 \%$ & $26.66 \mathrm{def}$ & 30.00 ef & 33.33 ef & $\begin{array}{c}36.67 \\
\text { def }\end{array}$ & $\begin{array}{c}40.00 \\
\text { def }\end{array}$ & $\begin{array}{c}43.33 \\
\text { def }\end{array}$ & $\begin{array}{c}46.67 \\
\text { cde }\end{array}$ & $\begin{array}{c}50.00 \\
\text { cdef }\end{array}$ & $\begin{array}{c}53.33 \\
\text { ef }\end{array}$ & $\begin{array}{c}56.67 \\
\text { def }\end{array}$ \\
\hline $50 \%$ & $33.33 \mathrm{~cd}$ & $36.66 \mathrm{~cd}$ & $40.00 \mathrm{~cd}$ & $43.33 \mathrm{~cd}$ & $46.67 \mathrm{~cd}$ & $50.00 \mathrm{~cd}$ & $53.33 \mathrm{bc}$ & $56.67 \mathrm{~cd}$ & $\begin{array}{c}60.00 \\
\mathrm{~cd}\end{array}$ & $63.33 \mathrm{~cd}$ \\
\hline $75 \%$ & $56.66 \mathrm{a}$ & $60.00 \mathrm{a}$ & $63.33 \mathrm{a}$ & $66.67 \mathrm{a}$ & $70.00 \mathrm{a}$ & $73.33 \mathrm{a}$ & $76.67 \mathrm{a}$ & $80.00 \mathrm{a}$ & $83.33 \mathrm{a}$ & $86.67 \mathrm{a}$ \\
\hline
\end{tabular}

Means in column followed by different letters showed significance at $5 \%$ level of probability

Table 2. Percent repellency of Momordica charantia over exposure time of ten days

\begin{tabular}{|c|c|c|c|c|c|c|c|c|c|c|}
\hline \multirow{2}{*}{$\begin{array}{c}\text { Concentration } \\
(\%)\end{array}$} & \multicolumn{8}{|c|}{ Percent repellency of Momordica charantia over exposure time of ten days } \\
\cline { 2 - 11 } & $\mathbf{1}^{\text {stday }}$ & $\mathbf{2}^{\text {nd day }}$ & $\mathbf{3}^{\text {rd day }}$ & $\mathbf{4}^{\text {th day }}$ & $\mathbf{5}^{\text {th day }}$ & $\mathbf{6}^{\text {th day }}$ & $\mathbf{7}^{\text {thday }}$ & $\mathbf{8}^{\text {thday }}$ & $\mathbf{9}^{\text {thday }}$ & $\mathbf{1 0}^{\text {thday }}$ \\
\hline $\mathbf{0 \%}$ & $0.00 \mathrm{k}$ & 0.00 & $0.00 \mathrm{i}$ & $0.00 \mathrm{k}$ & $0.00 \mathrm{k}$ & $0.00 \mathrm{k}$ & $0.00 \mathrm{j}$ & $0.00 \mathrm{j}$ & $0.00 \mathrm{i}$ & $0.00 \mathrm{k}$ \\
\hline $\mathbf{2 5 \%}$ & $\begin{array}{c}20.00 \\
\text { fgh }\end{array}$ & $\begin{array}{c}23.33 \\
\text { gh }\end{array}$ & $\begin{array}{c}26.66 \\
\text { gh }\end{array}$ & $\begin{array}{c}30.00 \\
\text { fgh }\end{array}$ & $\begin{array}{c}33.33 \\
\text { fgh }\end{array}$ & $\begin{array}{c}36.67 \\
\text { fgh }\end{array}$ & $\begin{array}{c}40.00 \\
\text { efg }\end{array}$ & $40.00 \mathrm{efg}$ & $46.67 \mathrm{gh}$ & $50.00 \mathrm{fgh}$ \\
\hline $\mathbf{5 0 \%}$ & $\begin{array}{c}30.00 \\
\text { cde }\end{array}$ & $\begin{array}{c}33.33 \\
\text { de }\end{array}$ & $\begin{array}{c}36.66 \\
\text { de }\end{array}$ & $\begin{array}{c}40.00 \\
\text { de }\end{array}$ & $\begin{array}{c}43.33 \\
\text { de }\end{array}$ & $\begin{array}{c}46.67 \\
\text { de }\end{array}$ & $\begin{array}{c}50.00 \\
\text { bcd }\end{array}$ & $\begin{array}{c}50.00 \\
\text { bcd }\end{array}$ & $56.67 \mathrm{de}$ & $60.00 \mathrm{cde}$ \\
\hline $\mathbf{7 5 \%}$ & $46.67 \mathrm{~b}$ & $\begin{array}{c}50.00 \\
\mathrm{~b}\end{array}$ & $\begin{array}{c}53.33 \\
\mathrm{~b}\end{array}$ & $\begin{array}{c}56.67 \\
\mathrm{~b}\end{array}$ & $\begin{array}{c}60.00 \\
\mathrm{~b}\end{array}$ & $\begin{array}{c}63.33 \\
\mathrm{~b}\end{array}$ & $70.00 \mathrm{c}$ & $70.00 \mathrm{c}$ & $73.33 \mathrm{~b}$ & $76.67 \mathrm{~b}$ \\
\hline
\end{tabular}

Means in column followed by different letters showed significance at 5\% level of probability

\section{Conclusions and recommendations}

It is concluded that tested botanical extracts possess repellent abilities and repel insects in stores such as Lasioderma serricorne. As the concentration (\%) of the botanical extracts and exposure period (days) of the adult beetles to the tested extracts increased the percent repellency also increased. Mentha 
longifolia proved to be high successful botanical extract against $L$. serricorne at the dosage rate of $75 \%$ during the tenth day of the exposure period. The other applied botanical extract i.e Momordica charantia (Bitter Gourd) has also the ability to show maximum repellent outcomes to the tested insect at the dosage rate of $75 \%$ at the tenth day of exposure. The tested botanical extracts showed their efficacy for controlling targeted insects in stores and could be served as an alternative repellent material for stored product insects. It could be desirable to examine the efficacy of such botanical materials on non-targeted living organisms while applying in IPM programs. Further research is necessary to probe the effectiveness of the tested botanical extracts (natural insecticide) as a substitute to the artificial chemical pesticides.

\section{Authors' contributions}

Conceived and designed the experiments: $S$ Ahmad \& M Saeed, Performed the experiments: W Kamal, Analyzed the data: $\mathrm{H}$ Zada, Contributed materials/ analysis/ tools: $\mathrm{T}$ Khan \& S Ullah, Wrote the paper: A Rehman \& A Latif.

\section{Acknowledgement}

The authors express their sincere gratitude to the agriculture department, University of Haripur for their support to achieve the above research work and also thankful to department of entomology The University of Agriculture Peshawar, Pakistan.

\section{References}

1. Ali M (1986). Growing area of tobacco in NWFP. Pak Entomol 1(2): 47-49.

2. Anonymous (2002). PTB advice to tobacco growers. ISSN 1563-9479.

3. Chaudhary MA (1980). Aggregate postharvest food grain losses in Pakistan. Dept Agri Marketing Uni Agri. Faisalabad. pp 66.

4. Khan I, Afsheen S, Din N, Khattak S, Khalil SK \& Lou YHY (2010). Appraisal of different wheat genotypes against angoumois grain moth, Sitotroga ceralella (oliv). Pak J Zool 42: 161-168.

5. USDA (1972). Stored tobacco insectsbiology and control. USDA Handbook. No. 233.

6. Ukih DA, Birkett MA, Bruce TJA, Allan EJ, Pickett JA \& Mordue AJ (2010). Behavioural responses of the maize weevil, Sitophilus zeamais, to Host (maize grain) and non-host plant volatiles. Pest Manage Sci 66: 44-50.

7. Cetin H, Erler F \& Yanikoglu A (2004). Larvicidal activity of a botanical natural product, Akse Bio2, against Culex pipiens. Fitoterapia 75: 724-728.

8. Nadra HAM (2006). Use of Sesbania sesban (L.) Merr seed extracts for the protection of wheat grain against the granary weevil, Sitophilus granarius (L.) (Coleoptera: Curculionidae). J Basic and Appl Sci 7: 121-135.

9. Joey PP, Thomas J, Mathew S \& Skaria BP (2001). Medicinal Plants. Int Trop Hort 449-632.

10. Kem SI, Park C, Ohh MH, Cho HC \& Ahn YJ (2003). Contact and fumigant activities of aromatic plant extracts and essential oils against Lasioderma serricorne (Coleoptera: Anobiidae). J Stored Prod Res 39: 11-19.

11. Dong ZJ, Cheng DQ, Dong SD \& Zhou YH (2004). Botanical pesticide research and application in tobacco pest control. Acta Tabacaria Sinica 10: 42-47.

12. Kestenholz C, Stevenson \& Belmain PC (2007). Comparative study of field and laboratory evaluations of the ethnobotanical Cassia sophera L. (Leguminosae) for bioactivity against the storage pests Callosobruchus maculatus (F.) (Coleoptera: Bruchidae) and Sitophilus oryzae (L.) (Coleoptera: Curculionidae). J Stored Prod Res 43: 79-86.

13. Hori M (2003). Repellency of essential oils against the cigarette beetle, 
Lasioderma serricorne (Frbricius) (Coleoptera: Anobiidae). Appl Entomol Zool 38: 467-473.

14. Mojtaba GJ, Ali AP \& Mohammad HS (2012). Repellent effect of sirinol (garlic emulsion) against Lasioderma serricorne (Coleoptera: Anobiidae) and Tribolium castaneum (Coleoptera: Tenebrionidae) by three laboratory methods. African J Biotechnol 11: 280288.

15. Hassan A, Lwande W, Ole-Sitayo N, Moreka L, Nokoe S \& Chapya A (1990). Weevil repellent constituents of Ocimum suave leaves and Eugenia caryophyllata cloves as grain protectants in parts of Eastern Africa. Discov and Inno 2: 9195.

16. Waller RA \& Duncan DB (1969). Abays rule for symmetric multiple comparison problem. J American Stat Assoc 14851503.

17. Mohiuddin S, Qureshi RA, Khan MA, Nisar MKA, Khatri LM \& Qureshi SA (1987). Laboratory investigations on the repellency of some plant oils to red flour beetle Tribolium castenum. Pak $J$ Sci and Ind Res 30(10):754-756.

18. Bhuwan BM \& Tripathi SP (2011).
Repellent Activity of Plant Derived Essential Oils against Sitophilous oryzae and Tribolium castaneum. Singapore J of Sci Res 1: 173-178.

19. Modraes NS (2001). Damege assessement of stored product pests of wheat and barley in Systane Region Iran. Proceeding of $15^{\text {th }}$ Iranian Plant Protection Congress. pp 85-144.

20. Asawalam. FH \& Lgwe U (2012). Insecticidal potentials of Curcma longa, rizhomes and cymbogon citrates leaves extracts against the khpra bettle on stored groundnut. J of Agri Sci 2(9): 534-538.

21. Al-Jabr AM (2006). Toxicity and repellency of seven plant essential oils to Oryzaephilus surinamensis and Tribolium castaneum. Sci J King Faisal Uni (Basic \& Appl. Sci.) 7(1): 14-27.

22. Damals (2011). Potential uses of turmeric (C. longa) products as alternative means of pest management in crop production. Plant Omics J 4(3): 136-141.

23. Uma DM \& Sujatha K (2013). Toxic effects of Curcuma longa different extracts on biochemical and enzymatic parameters of Tribolium castaneum. Inter J Innov Res 1(2): 36-39. 